\title{
MRS HOME
}

The moral and cultural construction of domesticity and respectability between the wars.

Rebecca Leach

School of Social Science and Public Policy, Keele University, Staffordshire, UK.

DRAFT: Do not cite without specific permission until published.

\section{Contact:}

Dr Rebecca Leach

Senior Lecturer in Sociology

School of Social Science \& Public Policy

Keele University

Keele

Staffordshire

ST5 5BG

UK

Email: r.leach@keele.ac.uk Tel: 0044 (0)1782733359 
MRS HOME

\title{
The moral and cultural construction of domesticity and respectability between the wars.
}

\begin{abstract}
:
This paper uncovers archive material from the Foundations of Sociology archive: the output of the Institute of Sociology (Le Play House), exploring the cultural constructions of gendered domesticity and respectability among the lives of the poor and poorly housed in Chester in the interwar period. Focusing on a discursive re-analysis of original photographs and research notes focusing on the interior material cultures of home, hygiene and decor, the paper demonstrates that the characterization of the poor as morally and decoratively 'failing' was embedded even in those 'action researchers' of the Institute who sought direct social change. Depicting household interior photographs, plans, hand-written commentary and personal material, the archive reveals another dimension of what is also a familiar, contemporary trope: the unwitting but damaging construction of the poor as Other.
\end{abstract}

Keywords: home, Institute of Sociology, Le Play House, poverty, domesticity, respectability, interiors, Chester, 1919-39 
Mrs Home: the moral and cultural construction of domesticity and respectability between the wars ${ }^{\mathrm{i}}$.

Mrs Home ... is very house proud and keeps her children wonderfully, but it's 'always washing day', and she is getting irritable, I could see.(Astbury \& Farquharson 1931b)

Mrs Home is a real person: or at least the pseudonym of a real person. Part of a 'local social survey' conducted in 1929-33 by the Institute of Sociology [IoS $]^{\text {ii }}$, she was a member of one of a number of families examined to scrutinise well-being, poverty and housing conditions in the working class communities of Chester. This survey was a distinctive, but now mostly unknown contribution to early $20^{\text {th }}$ Century social science from what is also a now mostly unknown group. Recent intellectual histories of sociology, in this journal and elsewhere (Scott 2007; Scott and Bromley 2013; Fyfe 2013), however, have begun to shine new light on the contribution of the IoS to emergent early $20^{\text {th }}$ century sociology and it is valuable therefore to re-examine their legacy. In this article, I will seek to demonstrate that the inclusion of Mrs Home within this neglected resource of social science data represents a particular narrative of domesticity that began to fix the location of gender and class in the early 20th century. This is neither the only source of this narrative, nor a particularly novel version of it; however, it is intriguing to explore the wide origins, the continuity and ubiquity of narratives of gendered respectability that are still very evident in British life.This paper explores the context in which the surveys were carried out, noting their similarities to earlier 'socially engaged' surveys of poverty and housing such as those by Booth, Rowntree and others. However, it also draws out their distinctiveness, especially the intimacy with which portraits of local life, ideas of home and domestic cultures are drawn. Taking the culturally critical position that in such intimate domestic spaces, the surveyors' representations of home life are as interesting as the details of what they found there, this paper suggests that the IoS was actively constructing notions of domestic respectability in its wake. In particular, the defining judgements made in the interviews, notes and photographs provide a very rich account of the prejudices and cultural attachments of the authors of the surveys, as much as the subjects. Both authors and respondents are wrapped up in a key pivotal moment, an intellectual homology in the emergent formalising structures of the twentieth century: both are essentially lingering Victorian cultures that are then rapidly wiped out by versions of mid-century modernism. As recent discussion of the IoS' 'place' in the emergence of sociology has highlighted (Fyfe 2014; Law 2005; Scott and Husbands 2007; Scott and Bromley 2013), their intellectual project ultimately 'failed' because it was the continuation of a 'gentleman (and gentlewoman) amateur' model of social science. Losing ground to the scientific rationalism of mid-century social policy and intellectual sociology - represented by Michael Young and the LSE (Platt 2013) - we can find traces of this homology of a 'long Victorian' century in both the representations of working class communities, and in the 'structure of feeling' embedded in domestic material cultures of those communities. On one side, a bourgeois reformist culture seeks to improve local respectability, yet fails to impact on the overall 
modernist agenda; on the other, lifestyles, tastes and practices appear 'stuck' in Victoriana because of poverty, yet - as we know from other research (Hughes and Hunt 1992) - people were desperate to modernise their own living standards.

In this paper, I suggest, first, that the IoS were constructing and reconstructing notions of domesticity and respectability - as part of this 'long Victorian meets modernity' context - in relation to particular moralities particular to their class and cultural context. Unsurprisingly, they configured the poor working class as a corollary in their own early twentieth century middle class view of domestic life. They did this through a moral lens - focused on hygiene and domestic respectability - and a cultural lens - focused on the aesthetic taste in the domestic life of the poor.

Second, however, the IoS approach is revealing in its richness, not just because of the detail it shows us of the poor, Northern working classes in the early 20th century - after all, much of this is already well-known but because of what the observation of that detail tells us about the continuous ideological framing of class and gender amongst the powerful. The IoS model of home was ultimately morally conservative and restated gender and domestic stereotypes. Further, as this paper demonstrates empirically, this vision was shaped by broader cultural tastes and patterns of material culture that configured the 'eye' of the middle class protagonists to notice the Victorian and 'old-fashioned' clutter of the working class home, in contrast to their own capacity to choose aesthetically and judiciously. In what follows, I draw out the relative aesthetic values evident in domestic tastes and practices that can be derived from archive images and associated material.

\section{Domestic taste: the long Victorian century in working class homes}

The stylistic context in which the IoS were viewing homes, was shaped by a series of important social contexts, not least the economic challenges of the interwar period. In this piece, however, I am focusing on two specific issues: domestic taste and notions of respectable domestic management. These two lenses are shaped by a series of well-documented socio-economic contexts, momentous historical shifts and cultural patters. In this section, I outline some of the stylistic context for the interiors shown in later sections. What is clear is that the houses of the working classes in this period are driven by the necessary mixed function of household labour in that rooms serve as both relaxation and workspace, but also that the notion of 'old-fashionedness' becomes a product of necessity: style is important, but in the early 1930s, it is still essentially late Victorian style that dominates. The familiar cluttered, layered, textured and dark Victorian parlour is counter to the dominant middle-class fashions of the 1920s and 30s, pursued with vigour by designers and media sources (Sugg Ryan 2007). Thornton describes shifts in interior design fashion, characterizing the classical and exotic influences that dominate:

"It means that there are variations in how much pattern the eye can assimilate: in the late Victorian period it was a great deal while in the 1930s it was very little”. (Thornton 1984: 8-9) 
The dominant British interior style, up until the 1920s, is characterized as a "tradition with no name" (Thornton 1984: 308), lacking in identity because its primary role at this point was to provide a counterfoil for the Modern Movement. Based on a variety of Beaux Arts styles, this 'Romantic Classicism' dominated Victorian households and continued to be the preferred style of any decoration in poor households up until well after the Second World War. The trend for draped and cluttered Victorian decoration, influenced by colonial, historical and scientific exoticism represents a zeitgeist of gentleman amateur pursuits. There is a homology between the 'glory hole' rooms of the amateur collector, the attempt at portraying imagined Turkish silk-lined tents in a cretonne curtain, and in the dark, textured turned furniture attempting to convey Gothic naturism . In continuing to demonstrate this style, as I will show later in the paper, working class families 'fail' to live up to the new class aesthetic favoured by the interwar middle class: 'good' furniture of inheritable quality, light and air afforded by space, and a European modern taste beginning to emerge in the more restrained neo-Classical details of a table leg, as we see in the exhibition room used for work and living by IoS researchers (see figure 14).

This stylistic choice is also a moral choice. Cohen (2006: 19) identifies the emergence of a postVictorian, post-evangelical consumer culture as crucial in the further 'moralisation' of household objects, in which it is not just cleanliness that is at stake but also taste and aesthetics themselves which serve to define morality and respectability.

"of household objects, in which it is not just cleanliness that is at stake but also taste and aesthetic instruction in taste was a moral necessity precisely because things had the power to influence people for good or for ill. ... The moralization of possessions reflected a broader, post-evangelical mindset, which granted to household objects sway over those who came into contact with them".

Further, Sugg Ryan (2007) extensively documents the interventions made by designers and design agencies to use moralizing domestic narratives to intervene not only in women's cleanliness, but also in their domestic management. While the group of working class women in this study were less exposed to such moralizing narratives, the key point here is that those judging them as researchers and social workers colluded with the broader trend of intervening in respectability through moral judgements over hygiene and taste.

This moralizing narrative was part of a broader 'modern' reconstruction of the idea of home alongside aesthetic modernism in the twentieth century. The cultural theorist Christopher Reed (2002), whose influential book 'Not at Home' charts the emergence of domestic space as the 'other' of modernity, reminds us that domesticity is not of the past, but the counterbalance to modernity's notion of urban space. Historians of the home (Vickery, 2009) remind us that the notion of the domestic had to be fashioned and reworked from the early modern period in Europe through to its consolidation as the Victorian bourgeois idyll. Reed adds a useful nuance to the debate, making the point that the specifically Modernist values of the early twentieth century avant-garde made a move to distance themselves and their ideas from the domestic. By default, in this cultural 
period of exploding Modernism, "being undomestic came to serve as a guarantee of being art" (Reed 2002: 35). Reed documents a series of artistic interventions at the turn of the century and beyond that relegate domestic cultures as antithetical to 'real' culture: from the Impressionist fetish for the outdoors, to Modernist architecture's mockery and hatred of domestic design, being merely "settings for birth and death" or "sentimental hysteria" (Loos and Corbusier, quoted in Reed 2002: 37).

While the Victorian benevolence demonstrated in the visions of the IoS is the core narrative, there is also a troubling under-narrative: a continuity in the discursive constructions of the poor that has recently hoved into view once again. This construction of respectability as a key part of Victorian culture - as highlighted by Kelley, for example, provides a: "focus on the late Victorian and Edwardian periods, a time at which workingclass domesticity was under particular scrutiny, and was beginning the long process of change brought by gradually improving material conditions and the emergence of a consumer economy. Within this context, the idea and practice of domestic cleanliness was richly symbolic, and fiercely contested". What we see, then, in interwar models of respectability, is a continuation of this 'long Victorian' culture, but also its engagement with a modernity focused on civilization, science and rational planning. The consequence is the consolidation of a model of women's responsibility for 'civilising' in domestic households, and the continuation of the counternarrative: those who fail become part of the 'feckless Other'.

As Kelley (2009: 725) points out, the management of housing is overlaid with the management of women's insertion into domestic ideologies, in which spotless homes should demonstrate spotless reputations, and in which work outside the home is supported by the apparent magical absence of any work in the home. We see this tendency many times in what follows, in which the evidence of work that intrudes into middle class notions of domestic harmony is called out:

"notions of cleanliness do nevertheless feature prominently within them. Such notions are couched in a very particular set of values founded not upon physical efficiency or the idea of hygiene that increasingly characterised official debates, but rather upon a recurring idealisation and sentimentalisation of the selfless and loving mother and her services to her family, services that included the work of cleanliness, and that used it as a badge of respectability in a network of community values" (Kelley 2009: 728).

Further, Kelley (2009: 727) draws attention to the irony of women in the late Victorian and Edwardian period breaking out from their own domesticity to engage in regulating that of other women: the social workers, teachers and charity providers who were precisely the kind of staff used by the IoS in providing research support.

\section{Interwar housing and privatism.}


"This new, aspirational, respectability emphasized high standards of personal and domestic hygiene, 'privatized' family- and home-centred lifestyles," (Scott 2008: 17).

A number of social historians have identified the inter-war period as a pivotal moment in the spreading of bourgeois suburban sentiments to working class communities. Partly driven by economics, partly by shifting social conditions and policies, cultural attitudes to domesticity and privatism become embedded in this period. For example, Scott $(2008,2013)$ points out that the period represents a turning point in which Victorian/Edwardian notions of independence from charity demonstrated by proud household management and self-sufficiency, lead to cultural and familial expressions of privatism in the form of household consumption, increasingly domestic cultural pursuits (as opposed to public entertainment) and family size limits. This is consolidated in the 1920s and 30s, when newer council housing expanded, along with new expectations of household 'amenities', followed by 'suburbanisation' in housing options for both working and middle class households (Scott, 2013). Further, Hughes and Hunt (1992) highlighted this notion of the increasing 'enclosure' of the working class family from the outside world, as they were moved out from close-knit inner urban areas, to council estates with more space but more responsibilities: "there was an increasing emphasis on the respectable working class family as an intense domestic unit enclosed from the wider world" (Hughes \& Hunt 1992: 92).

Skeggs (1997: 43) summarises this substantial social change to privatized domesticity as contributing to the cultural problematisation of the working class, focusing on mother-housewives whose job was perceived as educating away any "potential revolutionary force; second as diluters of civilization and respectability". Since the perceptions of upper class commentators was that not all women could be relied upon, advice and guidance on mothering, household management and domestic life became a key tool of moral and social change (Skeggs 1997: 47). Hygiene and domestic space became the territory in which the moral battle between a dangerous, dirty Victorian past, and a clean, modern, civilized future were played out, and working class women's homes were the prime target.

This concern to 'privatise' messy domestic life is evident in a complaint, in the 1930s, of the consequences of allowing working class families out on the street, which in the context of Chester's small city centre (see figure 1), where slum housing was adjacent to middle class shopping enclaves, was seen as a threat to moral and economic wellbeing:

"People from the clearance areas who could not afford council-house rents moved into formerly respectable neighbourhoods, where single rooms were sublet to whole families, so creating new areas of overcrowding. The results were evident in a complaint of 1937 that people in Watergate Street, Crane Street, Stanley Place, and Paradise Row stood in doorways with shawls over their heads, their children screaming, rolling iron hoops, and kicking footballs in the streets, or sitting in doorways. Such 
conditions, visible alike to shoppers and to tourists walking the city walls, were held to devalue Chester's attractiveness.” (Lewis and Thacker 2003: 39)

\section{The Chester Regional Social Survey}

In unpacking this rich data with a critical, cultural lens, I used the primary materials generated in one of many 'local social surveys' deposited in the Foundations of Sociology archive (the output of the IoS and its earlier incarnations) at Keele University. Re-analysing the Chester survey material, I focused on unearthing from the archive the final report but also the original 'raw data' accounts of domestic provisioning, household management and visual mapping/photography carried out by the original researchers. By analysing these texts as discursive constructions which indicate socio-historical tensions over class, gender and domesticity, I maintain that there is a long interwoven history of academic and reformist discourse which strengthens the moral order, even while trying to 'make a difference'. As part of the legacy of the 'Othering' of the poor by the middle classes, this visual history deserves an airing.

The IoS conducted a local social survey of Chester under the intellectual guidance of Alexander Farquharson, who designed the project and who took the photographs and drew up the house plans, with the social survey elements managed by B.E.Astbury, who was the secretary of the local council of social welfare using "the voluntary help of a number of social workers accustomed to home visiting" (Astbury \& Farquharson 1931: no page numbers) ${ }^{1}$.

In total, 13 families were included in the survey sample, from a range of districts in Chester, encompassing wage-earning families in skilled, semi-skilled and unskilled work. 12 husbands were alive but only three were described as in 'good health', mostly from industrial or poverty-related diseases or war injuries. All families, of necessity, were in contact with social workers and in need of (financial) 'assistance'. Housing was mixed between pre-1914 terraces in poor condition and council rented properties considered to have more 'modern' amenities. In 'sampling' the local families for inclusion, the IoS state their assumptions as to the moral character and domestic 'standards' of the group involved, reminding us that these are 'typical' of the area:

"It might be argued that the families selected were, therefore, in some respects abnormal: contact with social workers and social work might imply weakness of character or an incidence of ill health or ill fortune not normal in form or extent. The social workers who carried out the investigations were, however, unanimous in

\footnotetext{
${ }^{1}$ Farquharson was the last in a line of intellectuals who managed the Institute of Sociology from the end of the $19^{\text {th }}$ Century until its demise in 1951. With his wife, Dorothea, they ran the model 'local social survey' method, combined with 'field visit' travels from the Institute's base, latterly in Ledbury. Their activities used 'activist volunteers' usually women (social workers or teachers) to marshall qualitative and quantitative data about localities. This particular survey was commissioned by Chester's Board of Social Welfare in the spirit of wider social reform in this period, in particular to address poverty and housing need. The history and background to the IoS can be found in Evans (1986) and Scott and Bromley (2013), and the emergent history of UK social work as a voluntaristic rather than state practice is documented in Burt (2008).
} 
thinking (a) that the families dealt with could be taken as normal at least in the sense that their lives are typical of those of large numbers of Chester families; and $(b)$ that further they were 'good' families, ie that they represented on the whole recognisably good standards of conduct, household management, capacity for work and so on" (Astbury \& Farquharson 1931a : np).

The documents produced for the Chester report seem to suggest a moral role for these women: not just domestic guardians against filth, poverty and poor housing conditions, but often a heroic role in holding the family together in extreme hardship caused by their sick or absent husbands. As the introduction to the report points out, of the twelve husbands alive, only three are healthy enough to work: "six of the rest have suffered... from gas, shell-shock or other war disabilities, and one of these suffers from rupture; of the three remaining, one is blind in one eye, one has fistula with accompanying weakness and the last simply records ill-health" (Astbury \& Farquharson 1931a: np). Amongst the wider family, pneumonia and TB are common also, with children often sent away to sanatoriums or to lodge with family in 'healthier' areas.

One of the key interests in this study is the construction of domesticity engaged in by the IoS. In what remains of this paper, I will focus on the representation of domestic interiors in photographs and plans taken by the IoS researchers - exploring both the details contained within the images but also the framing of those images in the authorial judgements made by those researchers - in the form of captions added for research purposes by Farquharson.

In contrast, in the context of analysing redeveloping housing policies for a more aspirational interwar middle-class suburbia, Scott (2008: 105) notes that prior (Victorian) working class values favoured informality and self-reliance:

"Pre-1914 notions of working-class respectability have been characterized as emphasizing independence from state or charitable assistance — via membership of formal or informal mutual aid networks - thrift, living within one's means, and stoically tightening one's belt during hard times".

It is clear that these notions of independent respectability are reproduced in the visions of home produced in the IoS studies. Maintaining a primarily Victorian moral and domestic ethic, these northern working class communities were not remotely close to holding or achieving the aspirational values of new building schemes elsewhere. What was aspired for, by the IoS action researchers, was the improvement of the civic lot of slums, their residents capable of transformation by housing improvements and welfare. As Hughes and Hunt (1992) discuss in the context of slum clearance and re-housing in Manchester between the wars, this was intended as a progressive move. Freeing housewives from unduly gruelling labour was a central focus of interwar housing campaigns, but not, of course, freeing them from domestic labour completely.

The published work and survey material of the IoS is virtually unknown in sociological documentation of these historical shifts. This may be for various good reasons, such as the lack of clear purpose and indeed their repetition of issues already extensively raised by the earlier social surveys of Booth and Rowntree. As 
commentators (Scott \& Husbands 2007; Evans 1986) on the IoS point out, however, the methodology was prescient of later anti-positivist and action research models in inviting local volunteers to participate in creating the outcomes, and in marshalling cultural representation and participant observation alongside more orthodox sociological methods:

“...competent observers might photograph typical street corner gatherings, typical bands of youths... typical door crowds. Each institution might be asked to record its own activities in a series of photographs'. The preparation of exhibitions, which would then be displayed in the... the place where the survey was done is not far removed from some innovatory forms of contemporary ethnography." (Evans 1986: 29)

Osborne et al (2008: 523) describe this concern as focusing on "minoritarian forms of investigative personality". Certainly, the concern with the material detritus of everyday life, the detailed examination of what are often decried as epiphenomena of broader social forces and the internal cultures of the domestic have, recently, undergone a spectacular reinvention. As Puwar and Sharma (2012) discuss, a "curatorial sociology" is widely used, even if not yet mainstreamed. In presenting the data below, I demonstrate some of the minoritarian concerns of the Regional Survey movement in just one (of very many) detailed curations of locality, standards of living and material culture. However, in doing so, I aim to draw out the discursive construction of core notions of home, domesticity and respectability. I suggested that what emerges is a cultural and representational tension over the 'long Victorian century' that is evident as a consequence of poverty and the need for social reform. Reformers, such as Alexander Farquharson who had the strongest role in developing the regional surveys and was the photographer/commentator for most of the images, had in mind a particular version of domestic life which is found in their narrating of the poor Other. In this narration, the reforming upper middle classes, lacking a sociological framework on poverty and critical reflexivity, cannot escape their apparently benevolent, gentleman/gentlewoman amateur status that both documents and honours the poor in beautiful narrative detail but that ultimately diminishes their experience. In this sense, the work of the IoS itself has become the data, an outcome they perhaps did not intend but that helps us shape the sociological debate on cultures of representation, class and morality today.

\section{The Chester Family Houses: domestic and aesthetic respectability}

The IoS begin their housing survey by documenting the housing types occupied by the 13 families they studies, dividing them into early nineteenth century, later nineteenth century 'parlour' houses, larger terraces and newer council housing with provision for domestic work. They shift from functional debates to observations of material culture and aesthetics. One passage in particular is particularly telling in its aesthetic judgement. The author, discussing the interior, notes: 
"Our details of furniture are incomplete; in general terms, however, we may note the association between the older houses and old or old fashioned furniture. In the council houses new or almost new furniture obtained on the hire purchase system appears; the somewhat older house in study 311 also contains good recently-bought furniture. Older houses show examples of inherited furniture which may go back 70-80 years. With new furniture go wireless sets, gramophones and some economy in ornament with modern touches. The old house with old furniture is bestrewn with photographs, knick-knacks, cheap vases and colour-prints in the Victorian style. The rooms in the older houses often seem overcrowded with furniture but their small size must be taken into account” (Astbury \& Farquharson 1931a : np).

This association between the old and the old-fashioned reveals connections to the aesthetic and health presumptions which confirm wider messages connecting well-being to the emergent $20^{\text {th }}$ century modernism of the time: the notion of 'opening up' space for health (presumed to come from light and air) and the ridding of small rooms of the clutter of Victorian ornamentation (Hughes and Hunt 1992; Reed 1996). An interesting elision takes place between excess stuff (overcrowding not just with people, but with things), 'old fashionedness' and 'good' newness. This construction of the 'good' home takes a further turn in the ideas of household management as we will see in what follows.

"They were 'good' families, i.e. ... they represented on the whole recognisably good standards of conduct, household management, capacity for work and so on” (Astbury \& Farquharson 1931a : np). One of the interesting things about the construction of the account of these domestic lives is the 'wide-eyed' bourgeois view of the working classes in presuming what the 'good' constitutes. It is a truism to suggest that in the giving of help, the accounts may illuminate the cultural biases of both the helper and the receiver. Nevertheless this is precisely what is interesting here: the supportive engagements of the active researchers in this project reveal their own moral constructions of home, family and order.

The notes and narratives from the field notes of the researchers in the Chester survey demonstrate clear moral hierarchies cleanliness and possessions, often in the revelatory ideas of what the researchers saw as 'normal'. The experience of poverty is identified as a definitive lack or absence, of standards of taste and of household management. Moral and cultural framings occur in the physical depiction in a series of photographs to include the heroic skillfulness - or concomitant failure - of women as household managers, and their presentation of home, children, spaces, consumer objects and - in almost every case - household linens as evidence of their respectability - or fecklessness.

65. ... There are 3 families that set aside 9s. a week or more for clothes. ... the third (304) is a family with a definitely high standard of living; there are only 3 sons, 2 of whom are of apprentice age; all 3 are earning something and it is stated that the family plays indoor games and has an expensive (£4:10:0) wireless set; the expenditure on food per 'man' as well as the clothes stands high in relation 
to the other families; at the same time it is stated that the wife is an excellent manager, and it is clear that this high expenditure reflects general well-being rather than feckless extravagance or showiness beyond the family's means.

(Astbury \& Farquharson 1931a:, np, Section on household income and budgets)

\section{Mrs Farmer ${ }^{2}$}

[insert figure 2 about here]

[caption] Figure 2: "Mrs Farmer, John and Pansy at the door of their house. John (said to be ailing and therefore at home) wears shirt, waistcoat and short; Pansy has frock and pinafore but no underclothes." The older boy is smiling at the camera, as if perhaps nervous, excited or schooled to smile. The house is a typical terraced house, rented and so the flock wallpaper behind would have been a landlord's doing, probably a legacy from an earlier period when the houses were not considered slums. The picture is taken from some distance back - from the road, perhaps so as to include the full doorway, and indeed some of the character of the adjoining house. That adjoining door is fairly detailed and ornate, with an elaborate metal knocker, a ceramic door handle and mouldings on a fairly substantial piece of wood. This implies a certain amount of investment, but these houses are late Victorian and despite some robust building standards (for example as the picture demonstrates, the construction of these Victorian terraces involved double skin brickwork and decorative touches below the roofline), were regarded as inadequate housing in the 1930s (Scott, 2013). This is partly because of the lack of electricity, internal bathroom and toilet facilities, and it was regarded as cheaper and easier for councils to rehouse families in newer council housing. The contrast of this image with the slightly grubby family next door is perhaps indicative of a comment (intentional or not) on the decayed or still decaying grandeur of the area.

The boy and his mother might be holding back the little girl, not only resting their hands nearby. She is a toddler and might take the opportunity to streak out into the road; however, there is something in her apparent need to be out there. This is a generation who played in the road, who owned the street as their childhood realm, at first not straying too far from the house but eventually owning the whole neighbourhood in their own tribes. This street ownership by poor children is further claimed by the chalk marks to the left of the photo. This individual photograph is also part of a familiar narrative genre: the great documentary photo tradition (Aubert 2009; Agee \& Evans 1941) uses the trope of dirty children in the street as one of its key indicators: 'look at the dirty urchins with nowhere else to play'.

Here though, Mrs Farmer is holding back her daughter, in front of a well-decorated house, holding her back from urchin-status. In so doing perhaps she is stating publicly her own notion of respectability. She fails,

\footnotetext{
${ }^{2}$ The captions referred to are notes by the IoS researchers, accompanying the original photographs. They are included in the analysis along with the visual images. The full image - with original photograph and handwritten original notes are included here.
} 
ultimately, in the eyes of the IoS researchers. The damning comments attached to the photo by the IoS researcher highlight Pansy's failure to have underclothes, and John's “said to be” ailing . The judgement is subtly damning: the Farmers are trying hard, but not quite managing to be respectable.

In the context of the aims of the researchers and social reformers of the time, the intentions are clearly good ones: it was necessary to 'talk up' the poverty in order to demonstrate need. This is not to suggest that people here were not in need, but they are clearly on the margins of destitution rather than fully so. So the position of the viewer, the interviewer, is an ambiguous one: caught between the need to present their respondents and 'users' as both respectable and dissolute, they are caught up in a cultural bind: constructing the moral character of householders through their domestic and family presentations as both strong and weak simultaneously.

This 'documentary' ambiguity is further reflected in the genre of the 'doorstep portrait' which - as Aubert (2009) points out - both consumes and constructs the subjects in their diminished status. While allowing, according to Aubert's analysis, the customary negotiated 'decorum' of the frontal, eye-contact pose on the door step (in contrast to the more candid laundry-strewn scenes we will see later), nevertheless the researchers cannot resist reminding the viewer of the indecorous truth of Pansy's lack of underclothes.

Mrs Farmer, however, is presented elsewhere throughout the report with a 'heroic' gloss, a status only bestowed on a select few in this study, the 'remarkable household managers': her overcoming of poverty through thrift, efficiency and labour is upheld, and the family's capacity to thrive despite their circumstances is signalled via their cultural activities:

Farmer:

[budget] "leaving a balance of 1/10 for amusements and coppers for children"

"Mrs Farmer shops where she considers best and cheapest. Tomlin, Phillips, or from a cart daily. Rarely any fresh butter. But Farmer and the eldest child eat well. Mrs Farmer has nothing on the Hire Purchase system. 'It doesn't pay you,' but she puts 3/6 weekly into the Provident Clothing Club and that clothes the whole family and keeps them in boots too.

Recreation. The children go now and again to the Cinema, but she prefers them to go to little concerts, etc., in Hoole. They go to Sunday School as it gives her and her husband a bit of quiet on Sundays. Mr Farmer does not care for the pictures or Theatre but enjoys a 'nice walk' and likes his home. 'He's a good husband and a great help'. Mrs Farmer reads a bit-chiefly papers - but evidently takes an interest in things going on”. (Astbury \& Farquharson 1931a : np)

This moral 'character' is further noted in the judgements of Mrs Farmer's personality:

"A cheerful woman, determined to manage to the best of her ability. A good wife, talkative but bighearted and a woman of shrewd perceptions and education - a good vocabulary. Accustomed to a good home”. (Astbury \& Farquharson 1931a : np) 
Similar judgements of personal and spatial character are made about most of the other women in the survey.

\section{Mrs Home:}

If the Mrs Farmer represents heroic success and personalised 'character' in the face of need, the Homes likewise, demonstrate similar 'character' but in this case, the home interior comes to stand for moral character also.

\section{[Insert figure 5 about here]}

[caption] Figure 5: "Mr \& Mrs Home and the baby at the front door of their 'council' house. Note Mr Home's indoor dress."

Another front door shot, which tells us something about the 'placing' of home and family together, the identification of the two as one entity. In this construction, the people have become their home. There is also, perhaps, a tinge of barricading going on in this 'front door' shot, as in the Farmer's image, maintaining privacy by having the picture there and not inside, at home, doing homely things. The door acts as a visual frame and denotes them as the 'owners' (if not the actual Owners) of the property and what goes on there. Unlike the previous photo from the Farmers' house, this is front on - in contrast with that, as if what surrounds or adjoins this door is unremarkable (unlike the ornate door in the previous image).

Certainly barricading the door like this would indicate a symbolic no entry, but since the interviews (with interior shots) were within homes, researchers did gain entry. We know, also, from the IoS notes, that Farquharson himself was the photographer and commentator on many of the photographs. Nevertheless, the resilient door pose is partially hiding the private realm: potentially including mess from the baby, unwashed nappies, waste, that would give away too much messy normality. Instead, the formal pose framed by the door mimics the framing in the family portrait - the door itself requiring a closeness of positioning, a natural frame.

The house is unremarkable, except of course it demonstrates here the 'improvements' to buildings (although viewed through today's eyes, they look like poor quality and low budget improvements) in council houses: the metal framed, obscure glass window for what is presumably - significantly - an inside bathroom or toilet; the wire fence seemingly demarcating private outdoor space - a garden or yard.

$\mathrm{Mr}$ and Mrs Home themselves look cheerful if wary. Again though, the commentator notes - as if neutrally, but entirely judgementally - the failure of respectability: noting Mr Home's “indoor dress” is a comment on his not being at work.

\section{Home}

The house is a good new one; facing South-West. Kitchen-living-room, small back kitchen, passage, 3 bedrooms and bathroom over.

It is well-kept; linoleum on passage and kitchen floors, nice wall-papers; cheap leatherette-covered 'suite' in kitchen; the arm-chairs put up-stairs 'because the children will jump on them'; a dresser 
under the window (with no upright back to it) some pictures, an over-mantel and glass, vases, a nice clock, a treadle and a hand-sewing machine (the latter Singer) and evidences of the Father's musical proclivities. The little boy of four takes after him, wants the gramophone all the time. Home hopes to make himself a wireless when he can get straight.

Bright cretonne curtains in kitchen- the flower garden in front very well laid out and beautifully kept, vegetables at back. Onions, carrots, lettuce, peas, potatoes; the husband tends these. Mrs Home does all the flower part. She is very house proud and keeps her children wonderfully, but it's 'always washing day', and she is getting irritable, I could see. She needs a good rest, but can 't afford to go home to her mother.... (Astbury \& Farquharson 1931a : np)

\section{[Insert Figure 7 about here]}

[caption] Figure 7: "Interior of the Home's living room. Note the patent(?) stove and new fashioned furniture. The baby's pram is kept here and serves as a cot during the day. Note meal on table - no sign of table being 'laid'".

There is no-one in the interior shot, except for a tiny photograph of what looks like a smartly dressed man in a silver frame on the mantelpiece. Could this be a younger, dapper Mr Home? The interior is decorative and cared for - the polished fireplace and the tablecloth demonstrative of attention to domestic detail; the lace curtains at the window and the pictures, a plant in a large white pot on the table, evidence of someone with a 'parlour' mentality. The walls are decorated also but it is not clear who was responsible for this - there are painted or papered plain walls with a picture rail in a contrasting colour, a flowered border below and above, a printed wallpaper. There is some ornate and detailed furniture here - the over-mantel mirror and the new chairs contrasting with some of the older style chairbacks which are visible.

Yet the careful presentation here is contrasted with the details of daily life: some sort of lacy undergarment is drying in front of the range, and some gloves - presumably women's since they do not look like work gloves. Can we read from this that Mrs Home was a particular and elegant woman? The baby's pram is parked here in the day -the handle is just visible to the left of the plant, looking like a leaf. This photograph shows a gleaming room: everything shines. The exterior photograph seems incongruous next to this - the residents have demonstrated pride here and the IoS researchers note that it is well kept. It looks like a Victorian parlour in a small Victorian house, the polished and shining darkness of enclosed respectability. To the visiting IoS researcher however, this detail is not quite enough, Mrs Home's irritability, the failure to lay the table and her husband's 'indoor dress' pointing to their need to 'get straight'. Once again, the voice of judgement: despite all the refinement and care in this room, 'no sign of table being laid' observes the failure of accomplishing homely respectability, not its success. 


\section{Mrs Marsh:}

[insert Figure 8 about here]

[Caption] Figure 8: “The back garden of Mrs Marsh's house with Mrs Marsh herself. Note sliding sashes of windows in upper floor. The garden is poorly kept-see currant bushes. Note quantity of disused materials".

If Mrs Farmer and Mrs Home just pass muster as respectable, Mrs Marsh is a more serious victim of domestic judgement: the 'poorly kept' garden and 'disused materials' in 'quantity' are shown and commented upon as evidence of her disarray and need. The observer here shifts from general commentary on housing quality (the sashes) to broader judgement about standards. What is striking here is the position taken by the researchers: to have found this garden (and these other homes) 'wanting' or 'poorly kept' is to apply a very exacting decorative standard. That the garden is productive should be sufficient, one might imagine, in difficult economic times.

Yes Mrs Marsh redeems herself elsewhere - in keeping a 'spotless' home, being 'devoted' to her children and demonstrating her independent resilience, she joins the eligibility list:

Marsh

"Mother says she needs new bedding \& beds. Wants to have small food shop to sell pickled herrings, chips, peas, pickles etc..

Mrs Marsh described her husband as 'a good husband and man' and ' a patient sufferer'. Mrs Marsh herself is a fine independent character who dislikes asking for help and always wishes to re-pay. She is devoted to her children and is always trying to please them. Her home is spotless - it shines with cleanliness. She re-papered herself the room where her husband died.

House

The house contains living room with coal fire and good over in which Mrs Marsh bakes pies etc frequently. Scullery with water tap and sink; upstairs 2 bedrooms with double beds. Toilet in yard. Front door opens onto living room. (Astbury \& Farquharson 1931a: np)

\section{Mrs Walter:}

[Insert Figure 9 about here]

[Caption] Figure 9: "The living room of the Walter family. Note small chair for younger child and ironing on table - clothes rack above and picture on the wall."

In the view of Mrs Walter's home there is less direct judgement here, except perhaps for the visual depiction of 'ironing on the table' - an indication of things out of place. The cluttered appearance here indicates a working room - perhaps this is wash or ironing 'day'. It might even be interpreted positively - an indication of the hard-working respectability of the occupants (that they do iron and wash regularly). 
If the work is evident on the surface, a more intimate picture emerges just below: there is a fireguard here, protecting the small child who presumably sits in the small chair. More than one decorative item is on show here: a couple of pictures and a hanging plate. One picture seems to be a romantic scene of a man and a woman in a landscape, the other perhaps a woodcut or photographic landscape of large trees or a distant church. On the mantelpiece an ornate clock, perhaps carved from wood, or soft dark stone. And a shiny round object that could be a mirror but is more likely a tray. Indeed, the mantel has a multipurpose utilitarian feel in part things are stored here, not just displayed: the kettle is holding back some documents - perhaps the rent books, with the kettle itself storing the rent. Or perhaps this kettle is in use and just put here randomly to keep it to hand. Clothes are ironed and neatly folded on the back of chairs here or on the standing rack, yet some textile items are hung up on the cupboard doors or under the mantelpiece. The floor is bare and boarded, the walls papered in what may well be a 'modern' print. The flower border appears very similar to one in another house. The turned furniture is rustic and populist, not at all glamorous except for the rather lively flowered print on the padded chair. This is echoed in the trimming to the mantelpiece, perhaps a single colour printed fabric or even lace - as in many of these ordinary houses, a device to prevent dust and smut. The gate-leg table, the ironing, the two clothes racks indicate the necessity of multiple purposes for rooms in houses like this: cooking, eating, servicing in confined spaces in working class homes. The visual reading here, then, is of intimacy and labour: a home built on washing, ironing and daily connections to family.

Mrs Walter:

"On enquiry we found that everyone regarded the family as exceptional. The father is described as a good worker, steady, reliable and devoted to his children. The mother is an extraordinarily capable person, a brilliant manager, a devoted wife and mother. The children are healthy, well-behaved and three of them have won scholarships. The home is beautifully clean, simply but well furnished. Mrs Walter is exceptionally proud of her bedrooms and shewed [sic] them to the helper. She proudly shewed clean sheets, clean blankets and counterpanes. The vicar of the Parish considers Mrs Walter to be the ideal mother. He takes a great interest in the family. Clothing was given to Molly and boots for the younger children. Mrs Walter gladly gave us the budget and also a full account of how she feeds the children and manages generally.

We never trouble about pictures or theatres, enjoying ourselves at home with our happy family. They cost me very little in Doctor's bills. I suppose I am lucky to have them all here happy and well". (Astbury \& Farquharson 1931b: np)

Mrs Walter's family's 'exceptional' status is fully displayed: the mother 'extraordinarily capable', and not only labelled so by the vicar but confident enough to show even her most intimate items (bed sheets) as clean. Her thrift and organisation in managing her ten children into good clothing, good behaviour and scholarships is noted and her application for relief payments specifically for school clothing and school books 
highlights the focus on her status as a 'deserving' housewife - one who is successfully civilizing her many children through education and good conduct. It is hard to avoid, however, the image of the "proudly shewn bedsheets [sic]' as the defining material, moral message of Mrs Walter's story: intimate, private items, made public by well-intentioned but intrusive domestic interrogation.

\section{Mrs Renwick:}

[Insert Figure 10 about here]

[Caption] Figure 10: "The back kitchen of the Renwick's house. Note bicycle kept here because there is no outside shed; also position of stove and sink and use of shelves. Also cut paper which ornaments them. The electric meter (1/- in the slot) is seen above the shelf on the right."

Three images from Mrs Renwick's house are shown: two interior images and a house plan. We can see from the house plan and the housing description for the survey, that the Renwicks (family 301) lived in a newer council house - with internal washing facilities, electric light and both a front and back garden.

The decorative charm here is touching: a handcut paper motif carried out across all the shelves to provide a homely touch in a utilitarian room, but also providing dust protection for items on open shelves. Most of the walls appear whitewashed, except for where the bike and baskets are stored: perhaps a distinction between clean and dirty storage. The kettle is on the stove (with a pan and an iron), and above, on the shelf is a decorated tin of (presumably) tea. Another rectangular, lidded tin of some sort is to the right. Two well-used teacups hang on hooks. Behind the gas cooker, a large double spread of newspaper appears to be being held there by a broomstick and a pan lid. There may be a flue or chimney behind the cooker, poorly fitted, and the newspaper perhaps prevents the draughts, despite the obvious firehazard. Likewise there appear to be electric wires and gas pipes trailing across some walls, indicating the haphazard upgrading and potential danger of the space.

The researcher's account is more neutral than some of the others, observing the details of equipment and services here and not any significant judgement. In this reading, the voice of the image is intended to speak for poverty, an attempt at realism that outsiders would readily understand. In Mrs Renwick's front room, however, more judgement comes into play. A picture rail with geometric and flower print below with contrasting colours - light above, dark woodwork. An oval mirror hanging above the mantelpiece and more dust-preventing decorative detail on its edge: tassles or bobbles, to perhaps also reflect more textured and opulent tastes. The fabric choice is echoed in the table covering which appears to be a dark patterned fringed chenille or rough velvet. The same range fireplace and rustic turned furniture are found here as in a previous house. The floor may be boarded or laid with linoleum but there appears to be a hearthrug with a bold flowered pattern. There is no iron in sight but tiny white clothes are drying everywhere.

[Insert Figure 11 about here] 
[Caption] Figure 11: "The living room of the Renwick family. Note the convenient range, the ornaments, electric light and baby's knitted garments hanging on line. The table is too near the stove - its usual place is under the electric light. Note 'ironing' on table."

The commentary on the photo of the Renwick's living room again is mostly neutral, but the comment about the table being too near the stove gives a slight ambiguity: too near because the family are thoughtless, or too near because for the purpose of taking the photo it was moved? 'Its usual place' could be either: usual as in day to day, or usual as in 'where it should be' according to broader social custom. This room is labelled again as ambiguous: between success and failure of domestic respectability. On the one hand, it succeeds in being of high quality living space, with electric light and 'convenient' range; and the ornaments and washed clothing hint at the effectiveness of whoever put them there. But the table being misplaced and the ironing on the table serve to remind us, above all, of what is out of place: domestic respectability. The wider commentary in the survey notes on the Renwicks goes some way to explain their situation: although they ought to be thriving in their council house with assistance, the family is in debt because of the poor health of the couple: Mr Renwick, gassed during the war, suffering with TB and unable to work; Mrs Renwick, anaemic and exhausted from continuous pregnancies and undernourishment. While the survey holds up moral and aesthetic standards to the poor, it is also important to note that despite the breaking through of cultural prejudices and sensibilities, nevertheless, the intention of the survey - and those carrying it out - was an empathetic and altruistic one: to alleviate the suffering of the poor by shining a detailed light on what life was like for them.

\section{The Farquharsons}

In contrast to the commentary on working class homes, the archive delivers some insights into the aesthetic and moral sensibility of the IoS, derived from some personal documents, diaries and letters. The originator of the Institute of Sociology, Victor Branford, lived in various properties that befitted a mobile middle class intellectual of the early twentieth century: in Boundary House in Hampstead, a detached Arts and Crafts villa in the garden suburb that his wife, Sybella had written about in her own works (Scott 2007: 468, notes 481). There are hints that the upper middle class expectations of the Farquharsons in the later incarnations of the IoS were congruent with this cultured lifestyle. Images of Le Play house in both Malvern (see figure 13a) - in the interwar period - and later, Ledbury (see figure 13b), show large detached villas with extensive gardens, and we see a brief glimpse of interior life with a photo of the Exhibition Room (see figure 14) at Le Play House, Ledbury: the large handsome map desk, substantial sideboards, the leather chairs, the elegantly draped and delicately leaded windows, a woven rug, books and flowers signaling both care for potential visitors but also a spacious and well-provided for domestic aesthetic. The contrast with the damp, dark terraces of Chester could not be starker. 
Domestic choices and household management also reveal the class realities shaping the IoS view. Dorothea Farquharson's war diaries from the summer of 1941, when the IoS had moved to Malvern to escape the London bombings, document a bourgeois struggle to manage her own household and respectability, as she struggles to buy vegetables yet continues to buy the best Orange Pekoe tea from London, and explores the potential of moving the Institute to a country house, where there is a ballroom, grounds and the central difficulty is getting hold of staff. She writes:

“Weds. July 9. 1941. ... We went by taxi to look over a large furnished house at Malvern Wells called 'The House in the Wood'. It is near the Holy Well on Holywell Road. It is a wood alright: the garden is cut out of the wood. It belongs to this Delap [sic] who used to live at Livingstone Lovell [sic] when we were children at Buckingham. She left this house a year ago to join a friend in Cornwall. She will let if at 10 gns. a week (at a lower rate for any length of time) or sell it as it stands, gardener's cottage, garage and sleeping huts and acres of woodland and garden for $£ 4000$ furnished - included the Steinway grand piano and everything else. It is ideal for a house party or for research students. The difficulty might be service. It's a bit remote for maids. The two gardeners are included in rental. They keep the place going. I wish we could get someone in there who'd let it to us for two weeks at a time now and then for Field Study Meetings or conferences. The views over the Severn Plain to the Cotswolds are superb. The house is delightful-roomy, with good windows. Nine bedrooms and several studies or parlours and one large double drawing-room, a music room and a conference hall."

[Figures 13a and 13b about here]

[captions for figures 13a and 13b: Figure 13a: Le Play House, Malvern (1939 - temporary HQ and home to the Farquharsons.

Figure 13b: LePlay House, Ledbury (1939-1955 - IoS HQ until dissolution in 1955 and home to the Farquharsons), 1947 . In the lower picture, Dorothea Farquharson, can be seen standing in the doorway.]

[Figure 14 about here]

[Caption for figure 14: The Exhibition Room, Le Play House, Ledbury.]

Alexander Farquharson's personal documents also indicate an expectation of upper middle class comfort: his father's death prompted the sale of his childhood home (a Scottish manse) and its contents. The auction list (see figure 15) gives a detailed record of good furniture - presumably not good enough to be inherited - including a Dresden Saxony piano and walnut telescope table. These brief insights into the material comfort of the Farquharsons' domesticity help us to gain some critical distance from the apparently neutral vision found in the original research photographs and observations. 
[Figure 15 about here]

[Caption for figure 15: Sale items from Alexander Farquharson's childhood home, following the death of his father.]

\section{Conclusion}

This paper has demonstrated some of the discursive framings of the domestic lives of the poor, as lacking respectability both in terms of moral and aesthetic sensibilities. This lack is shown through the visual, notational and contextual tone found in the IoS archive material. This material was not intended to be part of the IoS' original research purpose, but reveals - with hindsight - the complex construction of domesticity in cultural documents. Placed alongside the broader context of a changing aesthetic and moral tone - from Victoriana to mid-century Modernism, from the concomitant reflection of the poor as a messy problem to the poor as an object for modern social reform - we can see in these documents that the Victorian sense of the poor's failure to be respectable carries through, and does not stop even as social, economic and housing reform is underway in the 1930 s. 


\section{References:}

Agee, J. and Evans, W. (1941). Let Us Now Praise Famous Men. Boston, Houghton Mifflin.

Astbury, B.E. and Farquharson, A. (1931a). The Chester Report. Institute of Sociology, Le Play House.

[LP/4/1/1/1/1/4/2/1, Foundations of Sociology Archive, Keele University]

Astbury, B.E. and Farquharson, A. (1931b). Notes prepared for The Chester Report. Institute of Sociology, Le

Play House. [LP/4/1/1/1/1/4/1/3, Foundations of Sociology Archive, Keele University]

Aubert, D. (2009). The doorstep portrait: intrusion and performance in mainstream American documentary photography. Visual Studies, 24(1), 3-18.

Burt, M. (2008). Social work occupations in England, 1900-39: Changing the focus. International Social Work, 51(6), 749-762.

Cohen, D. (2006). Household Gods: The British and Their Possessions. London: Yale University Press.

Evans, D. (1986). Le Play House and the regional survey movement in British sociology, 1920-1955.

CNAA/Birmingham Polytechnic, Unpublished MPhil Thesis. Accessed via www.dfte.co.uk/ios on 30/03/2014

Fuller, S. (2007). A path better not to have been taken. The Sociological Review, 55(4), 816-22.

Fyfe, G. (2014). A canticle for Branford and Geddes. The Sociological Review, 62(4), 898-907.

Hughes, A. and Hunt, K. (1992) 'A culture transformed? Women's lives in Wythenshawe in the 1930s', in A.

Davies and S. Fielding, eds. (1992) Workers'worlds: Cultures and communities in Manchester and Salford,

1880-1939. Manchester: Manchester University Press, 74-101.

Kelley, V. (2009). 'The Virtues of a Drop of Cleansing Water': domestic work and cleanliness in the British working classes, 1880-1914. Women's History Review, 18 (5), 719-735.

Law, A. (2005). The ghost of Patrick Geddes: Civics as applied sociology. Sociological Research Online, 10(2). www.socresonline.org.uk/10/2/law.html

Lewis, C. and Thacker, A. (eds.) (2003). 'Twentieth century Chester 1914-2000: Introduction'. A History of the County of Chester: Volume 5 Part 1, the City of Chester: General History and Topography, 239-240, London: $\mathrm{VCH}$.

Osborne, T., Rose, N. \& Savage, M. (2008). Reinscribing British sociology: some critical reflections. The Sociological Review, 56(4), 519-534.

Platt, J. (2013 [2003]). A Sociological History of the British Sociological Association. London, Routledge.

Puwar, N. and Sharma, S. (2012). Curating Sociology. The Sociological Review, 60(S1), 40-63.

Reed, C. (1996). Not at home: suppression of domesticity in modern art and architecture. London: Thames and Hudson.

Scott, J. and Husbands, C. (2007). Victor Branford and the building of British sociology. The Sociological Review, 55(3), 460-484. 
Scott, J. and Bromley, R. (2013). Envisioning Sociology: Victor Branford, Patrick Geddes, and the quest for social reconstruction. Albany, SUNY Press.

Scott, P. (2008). Did owner-occupation lead to smaller families for interwar working-class households?

Economic History Review, 61 (1), 99-124.

Scott, P. (2013). The Making of the Modern British Home. Oxford: Oxford University Press.

Skeggs, B. (1997). Formations of Class and Gender: Becoming Respectable. London: Sage.

Studholme, M., Scott, J. and Husbands, C.T. (2007). Doppelgangers and racists: on inhabiting alternative universes. A reply to Steve Fuller.The Sociological Review, 55(4), 817-822.

Sugg Ryan, D. (2007). The vacuum cleaner under the stairs: women, modernity and domestic technology in Britain between the wars. Online source: Falmouth University, www.repository.falmouth.ac.uk/514/ Thornton, P. (1984). Authentic Décor: The Domestic Interior 1620-1920. London: Weidenfeld and Nicolson. Trachtenberg, A. (1990). Reading American Photographs. New York, Hill and Wang.

Vickery, A. (2009) Behind Closed Doors: At Home in Georgian England. London: Yale University Press. 


\section{List of Figures \& Captions:}

Italicised captions are those accompanying the original photographs from the survey notes

Figure 1: Chester town centre street plan from the housing survey.

Figure 2: "Mrs Farmer, John and Pansy at the door of their house. John (said to be ailing and therefore at home) wears shirt, waistcoat and short; Pansy has frock and pinafore but no underclothes."

Figure 3: Farmer family house plan.

Figure 4: Farmer family street aspect.

Figure 5: "Mr \& Mrs Home and the baby at the front door of their 'council' house. Note Mr Home's indoor dress."

Figure 6: Home family house plan.

Figure 7: “Interior of the Home's living room. Note the patent(?) stove and new fashioned furniture. The baby's pram is kept here and serves as a cot during the day. Note meal on table - no sign of table being 'laid'." Figure 8: “The back garden of Mrs Marsh's house with Mrs Marsh herself. Note sliding sashes of windows in upper floor. The garden is poorly kept-see currant bushes. Note quantity of disused materials."

Figure 9: "The living room of the Walter family. Note small chair for younger child and ironing on tableclothes rack above and picture on the wall."

Figure 10: "The back kitchen of the Renwick's house. Note bicycle kept here because there is no outside shed; also position of stove and sink and use of shelves. Also cut paper which ornaments them. The electric meter (1/- in the slot) is seen above the shelf on the right."

Figure 11: "The living room of the Renwick family. Note the convenient range, the ornaments, electric light and baby's knitted garments hanging on line. The table is too near the stove - its usual place is under the electric light. Note 'ironing' on table."

Figure 13a: Le Play House, Malvern (1939 - temporary HQ and home to the Farquharsons.

Figure 13b: LePlay House, Ledbury (1939-1955 - IoS HQ until dissolution in 1955 and home to the Farquharsons), 1947 . In the lower picture, Dorothea Farquharson, can be seen standing in the doorway.

Figure 14: The Exhibition Room, Le Play House, Ledbury.

Figure 15: Sale items from Alexander Farquharson's childhood home, following the death of his father.

\footnotetext{
' Permission to use these images was given by Keele University Library, Foundations of Sociology Archive and I am grateful to Helen Burton, archivist, for her help.

ii Throughout this paper I use the term Institute of Sociology (IoS) to describe the organisational group conducting this research. The original research was carried on in a period just on the cusp of a change in organisational structure, from the Sociological Society/Le Play House, to the establishment of the IoS in 1930. Because the Chester study was published formally after the establishment of the IoS, I use this term throughout for convenience.
} 